\title{
The long-term effects of military conscription on educational attainment and wages
}

\author{
Frank Hubers ${ }^{1 *}+$ and Dinand Webbink $k^{1,2,3+}$
}

${ }^{*}$ Correspondence:
f.r.hubers@gmail.com
${ }^{\dagger}$ Equal Contributors
${ }^{1}$ Erasmus School of Economics,
Rotterdam, Netherlands
Full list of author information is
available at the end of the article

\begin{abstract}
This study investigates the long-term effects of peace-time military conscription on educational attainment and earnings by exploiting a policy change that exempted a complete birth cohort from military service. We find that compulsory military service decreases the proportion of Dutch university graduates by 1.5 percentage points from a baseline of 12.3 per cent. In addition, being a conscript reduces the probability of obtaining a university degree by almost four percentage points. The effect of military service on earnings is also negative and long-lasting. Approximately 18 years after military service, we still find a negative effect of 3 to 4 per cent. The effect of conscription on educational attainment does not fully explain the wage reduction.
\end{abstract}

Jel classification: $\mathrm{H} 56$; J31; J24

Keywords: Military conscription; Long-term earnings; Human capital; University enrolment

\section{Introduction}

Many countries have a military draft that compels large populations of young men to spend a substantial period of time in military service. Conscripts typically have to serve in the army in a period of their life in which decisions on human capital investments are taken. A compulsory military draft might harm investments in human capital and reduce life time earnings. A number of recent studies have investigated the effect of military service on educational attainment or the effect on wages. Remarkably, these studies do not provide a consistent picture of the effects of military service. For instance, military service seems to decrease educational attainment in the UK (Buonanno 2006) and Italy (Cipollone and Rosolia 2007) ${ }^{1}$ but increase completion of tertiary education in Germany (Bauer et al. 2014), France (Maurin and Xenogiani 2007) and in the US (Card and Lemieux 2001) because of draft avoidance behaviours. In addition, military service seems to reduce wages in the US (Angrist 1990; Angrist and Krueger 1994) and in the Netherlands (Imbens and van der Klaauw 1995), but in Germany (Bauer et al. 2012), there is no effect on wages. In the US, the negative effects seem to fade away over time (Angrist et al. 2011). Moreover, the importance of education as a mediating channel for the long run effects on earnings remains unclear (Bauer et al. 2012).

This paper aims to provide new evidence by investigating the long term effects of military conscription on educational attainment and wages in the Netherlands. Investigating the effects of military conscription is difficult because those that have served might differ

(c) 2015 Hubers and Webbink; licensee Springer. This is an Open Access article distributed under the terms of the Creative

Commons Attribution License (http://creativecommons.org/licenses/by/4.0), which permits unrestricted use, distribution, and reproduction in any medium, provided the original work is properly credited. 
from those that have not served. Despite the fact that military conscription was compulsory for all men in the Netherlands, only 40 per cent of each birth cohort actually served in the military. Those who were recruited were selected from a larger population and the various decisions made in this selection process are unobserved. This might induce selection bias if we compare the outcomes of those who served in the military with the outcomes of those that did not serve in the military.

To address this selection problem, we exploit a policy change that created a major difference in conscription between birth cohorts. In 1979, the age that Dutch young men were called for military service was lowered from 20 to 19 . The direct consequence of this policy change was that a whole birth cohort was exempted from military service. We identify the causal effect of military service by comparing the long term outcomes of this exempted birth cohort with the outcomes of those born in the adjacent years. This local comparison enables us to generate two types of estimates. First, reduced form estimates of the difference between the exempted cohort and the adjacent cohorts that received the regular treatment of conscription provide a direct estimate of the societal costs of a system of conscription. The societal costs might consist of a lower educated population with a lower earnings capacity. Second, instrumental variable estimates show the effect of conscription for males that actually served in the army. These estimates for the compliers provide insight into the private costs of conscription. This approach is related to earlier work by Imbens and van der Klaauw (1995). They introduced an instrumental variable approach that exploits all variation in conscription between fourteen birth cohorts for obtaining estimates of the short term wage effects for conscripts. We also apply their approach for testing the robustness of our main results on the long term effects of conscription on three education outcomes and wages using micro-level data from 1997 to 2002. Moreover, data on educational attainment and earnings of women enable us to perform a placebo test about the influence of other time related confounding factors.

This paper contributes to the recent literature on the effects of military service. First, by exploiting variation in conscription that is transparent and arguably exogenous in a local approach, we are able to obtain estimates of both the societal and private costs of a system of compulsory military service. Second, we are able to trace the effects of conscription on investment in human capital. In particular, we are able to investigate the effects of military conscription on completion of university education. We find that the system of compulsory military service decreases the proportion of university graduates by 1.5 percentage points from a baseline of 12.3 per cent. In addition, being a conscript reduces the probability of obtaining a university degree by almost four percentage points. Third, we investigate the long term effects of conscription on the average societal wages and the wages of conscripts. We find that the system of military service reduces average societal wages by 1.5 per cent. In addition, conscripts lose approximately four per cent of their wages by serving in the military. This suggests that the negative effects of military service are long-lasting. Finally, we investigate to what extent the wage costs of conscription can be explained by the decrease in investment in human capital. We find that the effect of conscription on educational attainment does not fully explain the wage reduction. This suggests that conscription also reduces individual earnings capacity through channels other than a reduction in human capital.

The remainder of the paper is organised as follows. The next section will provide background information about military conscription in the Netherlands. Section 3 discusses 
previous research on the effects of military conscription. Section 4 explains our empirical strategy. The data are described in Section 5. Section 6 shows the main estimation results, and Section 7 shows the results of several sensitivity tests. Section 8 concludes.

\section{Background}

The Netherlands has had a system of military conscription for almost two centuries. It was introduced by Napoleon in 1810 when the Netherlands was under French rule. It was only in the 1990s that Dutch politicians started seriously questioning the need for a large drafted army. The fall of the Berlin wall and the end of the Cold War had diminished the fear for a military invasion. Eventually, military conscription was abandoned in the Netherlands in $1997^{2}$.

Military conscription is part of the political ideal of the nation-state, in which all citizens alike have the duty to protect their fatherland. The advantages of the draft system for the state are evident; the supply of cheap labour provides the state with a large army. However, the military conscription system is also criticized. First, the draft system might induce an inefficient match of jobs and people. Recruits are rather arbitrarly allocated to a job without proper consideration of productivity, comparative advantages and outside options (Lau et al. 2004). This inefficiency might also be linked to the fact that serving in the military was for many recruits a long period of boredom (Duindam 1995). The second implication of the draft is that it can be regarded as a hidden tax, unequally distributed among the population. The state forces young men to work for a certain amount of time for wages that are probably much lower than they could have earned in the labour market. This difference can be regarded as a tax for the young men that have to serve (Lau et al. 2004; Poutvaara and Wagener 2007; Poutvaara and Wagener 2011).

In this study, we investigate the long term effects of the Dutch military draft system from the period between 1970 and 1990. Since the Netherlands was not involved in any wars during this period, our analysis is about the effects of peace time conscription. During this period, the military consisted of almost 50 per cent conscripts. At the age of 17, Dutch males received a letter from the Dutch Ministry of Defence about the registration as a recruit and duties and procedures of conscription ${ }^{3}$. The medical and psychological examination took place in the year the potential recruit turned 18. On average, 30 per cent of the potential recruits were immediately exempted from military service. The reasons to be exempted varied. These could be serious medical conditions or 'psychological instability' but also less obvious 'medical conditions' such as being at least 2 meters tall. The 'psychological instability' exemption became notorious since many attempted to be exempted via this route by pretending to be mentally ill. Those who passed the medical examinations were considered fit to serve and were supposed to wait until they were called for service. During this period, the recruit could still opt for other reasons to be exempted. Some reasons to be exempted were being enrolled in tertiary education or being the sole breadwinner in the household. Although most exemptions were temporary, in practice, they often became full exemptions since men were rarely called for service after their $26^{\text {th }}$ birthday. A special case was the conscientious objector, who refused to perform military service out of principle. Conscientious objectors were granted an alternative social or civilian conscription. Those considered fit to serve were called for military service in the year they turned 19. The recruits that were called for service generally served in the military for 14 months. About 15 per cent of the recruits were invited to 
be trained as officers. This meant slightly better pay, but also serving for 16 instead of 14 months.

From 1969, the military was confronted with a structural surplus of recruits, caused both by a decreased demand - a result of budget cuts which allowed a maximum of 45,000 recruits annually - and an increasing supply of recruits because of the post-war birth wave (Hoffenaar and Schoenmaker 1994). A number of policies were implemented to reduce this surplus. The first was the introduction of the so called 'special exemption' category, which consisted of a random selection of men from those who were fit to serve. Being 'specially exempted' implied that the recruit was not called for duty except in the case of an emergency. The second policy was a change in the conscription age, which was lowered from 20 to 19 from 1979 onwards. Although the official reason for this change in policy was to improve the transition from secondary school to military service, an important side effect was that birth cohort 1959 was completely exempted from military service. In 1978 all those turning 20 that year were called for military service (birth cohort 1958) while in 1979 all those turning 19 were called for service (birth cohort 1960). We will exploit this shock in our empirical model.

\section{Previous studies}

\subsection{Conscription and educational attainment}

Several studies have assessed the effects of military conscription on educational attainment. In general, the evidence seems mixed as some studies report a negative effect of military conscription, whereas other studies find that military conscription induces an increase of enrolment in tertiary education. Keller et al. (2009) compare European countries since the 1960s and find a strong negative association between enrolment in tertiary education and the share of recruits in a country. Buonanno (2006) finds that that exemption from military service in the UK increases educational attainment by approximately a quarter of a year. However, for Italy, no effect of military conscription on enrolment in tertiary education is found, except for recruits from lower socio-economic backgrounds (Di Pietro 2013). Cipollone and Rosolia (2007) exploit regional variation in military conscription in Italy and find that military conscription also has a negative impact on male high school graduation. Remarkably, they also find a positive effect on graduation rates of girls from the same areas and cohorts. Positive effects of military conscription on completion of tertiary education have been reported for France (Maurin and Xenogiani 2007), for the US (Card and Lemieux 2001) and for Germany (Bauer et al. 2014). These effects seem to be driven by draft avoidance behaviour.

\subsection{Conscription and earnings}

A number of studies have focused on the effect of military conscription on future wages. These studies find mixed effects, ranging from zero to a negative effect. Imbens and van der Klaauw (1995) find that being conscripted in the Netherlands reduces earnings ten years after conscription by almost 5 per cent. Findings for the United Kingdom suggest that military conscription reduces wages by 4 to 7 per cent (Buonanno 2006). However, several other studies do not find an effect of military conscription on wages. For instance, Grenet et al. (2010) do not find a reduction of wages for conscripts in the United Kingdom. In addition, peace time conscription seems not to harm future wages in Germany (Bauer et al. 2014, 2012). Moreover, for Australian recruits no negative wage effects have been 
found for military conscription in the Vietnam-era (Siminski 2013). For the US, there seems to be a negative short term effect that fades out over time. Angrist (1990) shows that ten years after service during the Vietnam War, veterans earn 15 per cent less than those who didn't serve. However, in the long run, these adverse consequences of conscription seem to fade out (Angrist et al. 2011). A study of the medium and long term effects of conscription in the Second World War finds no significant differences between veterans and non-veterans (Angrist and Krueger 1994).

In sum, previous empirical studies suggests that military service, both in peace time as in war time, has either no effect or a negative effect on future earnings. The negative effects might result from the effect of conscription on human capital. Conscription might diminish individual returns on human capital, which in turn affects the future wages of a recruit (Lau et al. 2004; Poutvaara and Wagener 2007; Poutvaara and Wagener 2011). Young men are typically called for military service during a period of their lives that would otherwise be devoted to learning or gaining work experience. In addition, human capital accumulated before the draft might depreciate during military service. If military service causes a break in the educational career, it is likely that more time will be needed for completion of tertiary education and might therefore reduce the probability of enrolment and completion of tertiary education. On the other hand, the conscription system in the Netherlands gave recruits the opportunity to postpone their military service duties until they finished their tertiary education. In practice, this often led to a full exemption as a recruit older than 26 was considered too old to serve in the military (Hoffenaar and Schoenmaker 1994). Draft-avoidance behaviour may therefore just as well have led to an increase in enrolment in tertiary education in the Netherlands.

\section{Empirical strategy}

This study aims to estimate the effect of military conscription on education and wages. The most straightforward way to estimate the effect of conscription would be to regress the outcome variables on a dummy variable for serving in the military using the following equation:

$$
Y_{i}=\beta_{0}+\beta_{1} S_{i}+\beta_{2} X_{i}+\varepsilon_{i}
$$

in which $Y_{i}$ is the dependent variable, for instance earnings or education, $S_{i}$ is a dummy variable equal to 1 if individual $i$ served in the military and 0 otherwise and $X_{i}$ is a vector of covariates. The regression above would give an unbiased estimate if serving in the military could be considered as a random event. This is unlikely to be the case because of the complicated selection procedures and the various opportunities to be exempted from military service. For instance, individuals with specific - unobserved - skills may have been more successful in exploiting these exemptions than others. We may therefore not assume that $S_{i}$ is uncorrelated with $\varepsilon_{i}$.

To address this endogeneity problem, we exploit a policy change that exempted a complete birth cohort from being conscripted. From 1979 onwards, the age that men were called for military conscription was lowered from 20 to 19. As a consequence, the complete birth cohort of 1959 was exempted from military service. Hence, this policy change creates a transparent counterfactual for regular cohorts that had to serve in the army. This variation can be considered as random because it is driven by a governmental decision which is likely to be unrelated with individual (unobserved) factors. We can assess the 
effect of conscription by comparing the outcomes of the cohorts born around 1959. For this comparison, we estimate reduced form models that include a dummy for being born in $1959\left(b c 1959_{i}\right)$ and controls for a smooth function age $\left(f\left(A_{i}\right)\right)$ and other covariates $\left(X_{i}\right)$ :

$$
Y_{i}=\delta_{0}+\delta_{1} b c 1959_{i}+f\left(A_{i}\right)+\delta_{2} X_{i}+v_{i}
$$

The parameter $\delta_{1}$ captures the effect of being born in 1959. This effect can be attributed to the system of conscription if we assume that the schooling and earnings capabilities of males born in 1959 are not different from the capabilities of males born in the adjacent years before and after 1959. If $b c 1959_{i}$ is a dummy variable equal to 1 if individual $i$ is born in 1959 and 0 otherwise, the estimates of $\delta_{1}$ can be interpreted as the societal effect of not having a system of compulsory military service. For instance, if the average wage of males born in 1959 are higher than the wages of those born in adjacent years, this can be interpreted as the societal costs of a system of conscription. The adjacent cohorts would have earned the same wages as males born in 1959 if there had not been a system of compulsory military service. It should be noted that the policy change exploited in this paper creates a discontinuity in the probability of serving in the army that had a duration of one year only. After this year, the probability of serving in the army returned to the regular level. In the standard regression discontinuity models, as for instance applied by Bauer et al. (2012), the probability of serving in the army only changes once. Our application provides the opportunity to use before and after cohorts for comparisons. This makes the estimates less vulnerable for functional form assumptions, for instance, about the specification of age. In addition, we can apply a local approach by using discontinuity samples of birth cohorts around 1959 for our estimation ${ }^{4}$. Estimation of Equation (2) is based on the exclusion restriction that the change in outcomes between birth cohort 1959 and the adjacent birth cohorts can be fully attributed to military conscription. In our sensitivity analysis, we will test this assumption by investigating differences between cohorts of women that were not subject to the conscription laws.

Imbens and van der Klaauw (1995) applied an approach in which the proportion of men that served in a specific birth cohort $\left(\bar{S}_{i}\right)$ was used as an instrument:

$$
\begin{aligned}
S_{i} & =\alpha_{0}+\alpha_{1} \bar{S}_{i}+f\left(A_{i}\right)+\alpha_{2} X_{i}+\varepsilon_{i} \\
Y_{i} & =\beta_{0}+\beta_{1} \hat{S}_{i}+f\left(A_{i}\right)+\beta_{2} X_{i}+\eta_{i}
\end{aligned}
$$

An innovative feature of the IV-approach of Imbens and van der Klaauw (1995) is that they were able to apply this approach without observing whether an individual had served in the army. Their key insight is that the expectation of $S_{i}$ conditional on the proportion that served from their birth cohort and covariates is equal to the proportion of the birth cohort that actually served because all regressors remain constant within each cohort, hence $E\left(S_{i} \mid \bar{S}_{i} X_{i}\right)=\bar{S}_{i}$. This implies that $\alpha_{1}=1, \alpha_{0}=\alpha_{2}=0$, and $\hat{S}_{i}=\alpha_{1} \bar{S}_{i}=\bar{S}_{i}$. Hence, the causal effect of conscription can be estimated with the following equation:

$$
Y_{i}=\beta_{0}+\beta_{1} \bar{S}_{i}+f\left(A_{i}\right)+\beta_{2} X_{i}+\eta_{i}
$$

Imbens and van der Klaauw (1995) estimated this equation using aggregated wage data (monthly birth cohort averages) from 1989 and 1990. We will estimate a local approach of the model of 1995, focussing on birth cohort 1959 and the adjacent cohorts. This approach is similar to Equation (2) but uses $\bar{S}_{i}$ instead of the variable $b c 1959_{i}$. For the estimation, we use discontinuity samples that include only one, two or three birth cohorts around 1959. 
In our sensitivity analysis, we replicate the models of Imbens and van der Klaauw (1995) to test our main assumptions by performing 'placebo tests' using data of women.

In sum, we estimate reduced form models of the effect of conscription on education and wages (Equation (2)). These estimates can be interpreted as the societal impact of conscription. In addition, we estimate the long term effects for conscripts by using an instrumental variable approach (Equation (4)).

\section{Data}

The data that are used in the analysis come from the so-called Wage Structure Survey $(\mathrm{LSO})^{5}$ that includes individual-level data on wages, education and background characteristics. Data on wages are obtained through the annual survey on employment and wages among firms and partly through administrative data on the insured workers. This means that all information on wages comes from administrative sources (firms or administrative data on insured people). This dataset also contains information on gender, age and job characteristics. Data on education are obtained from the annual labour force survey and are matched with the wage data. This matched data-set is called the Wage Structure Survey. We obtained data from the surveys of 1995, 1996, 1997 and 2002. These yearly surveys consist of approximately 125,000 individuals.

\subsection{The outcome variable}

For our first outcome variable, educational attainment, we can use three indicators: years of education and completion of two types of tertiary education (higher professional education or university education). Education is measured with a 16-point scale which is translated into years of education. Dutch tertiary education consists of two levels: higher professional education and university education. The first type of tertiary education has a vocational orientation and is considered to be the lowest level. University education has an academic orientation. Our second outcome variable is (log) annual wages. Our data contain the gross annual wages of 1995, 1996, 1997 and 2002. The data on wages from 1995-1997 have been converted from guilders to euros.

\subsection{The independent variable}

In the analysis, we exploit variation in the proportion of conscripts between birth cohorts for identifying the effect of conscription. The year of birth has been registered in our data. In addition, we use information on gender and the year of the survey. Information about the proportion of males per birth cohort that served in the army was derived from Imbens and van der Klaauw (1995), who obtained this information from the Dutch Ministry of Defense. Data for the years since 1969 proved not to be available at the Dutch Ministry of Defense. The proportion of men that served in the army for the birth cohorts 1956 to 1969 is shown in Figure 1. The proportion of men that received a special exemption status is shown in Figure 2.

Summary statistics of the main variables are shown in Table 1 and Figures 3 and 4 . These statistics also give a first impression of the effect of conscription on educational attainment and earnings. Table 1 shows summary statistics after pooling the four yearly LSO datasets. The four columns show the means for males born in 1959 and the means for the two, four or six adjacent male birth cohorts. We observe that males born in 1959 more often complete tertiary education, especially university education, than males born in the 


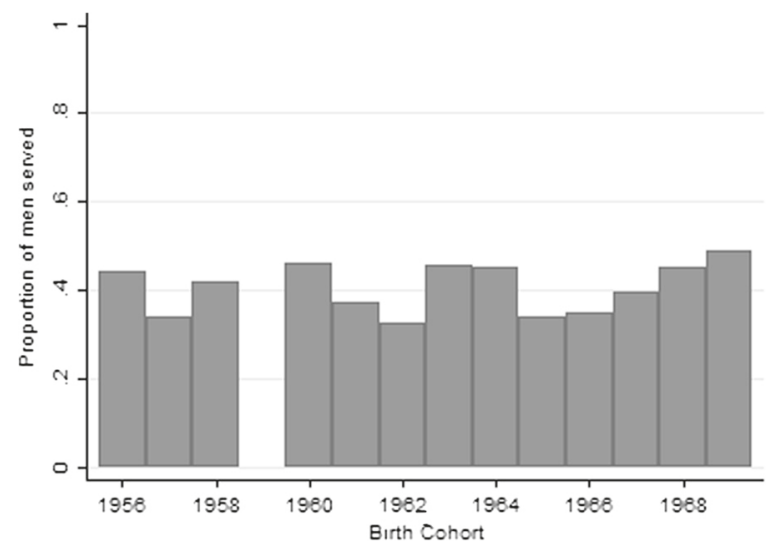

Figure 1 Proportion of Dutch men that served in the military by birth cohort.

adjacent years (columns (2), (3) and (4)). In addition, we observe that the annual earnings of males born in 1959 are higher than the annual earnings of those born in the adjacent birth cohorts. Figure 3 shows the proportion of the Dutch population that completed tertiary education by birth cohort. The vertical bars are based on a regression of completion of tertiary education on birth cohort adjusted for a quadratic function of age. We observe that birth cohort 1959 deviates most from the expected value based on the age profile. Figure 4 shows the gross average wages of men per birth cohort. This graph is based on the combined LSO data of, respectively, 1995, 1996, 1997 and 2002. As in Figure 2, the bars in Figure 4 are based on a regression of wages on birth cohorts adjusted for a quadratic function of age. Figure 4 shows that the average annual income for those born in 1959 is above the earnings prediction based on a quadratic age curve. The summary statistics shown in Table 1 and in Figures 3 and 4 suggest a negative effect of conscription on educational attainment and earnings.

\section{Main estimation results}

This section shows the estimates of the models that only exploit the variation due to the policy change that exempted all men born in 1959 from military service. The estimates are obtained by using local discontinuity samples of one, two or three years around the exempted cohort.

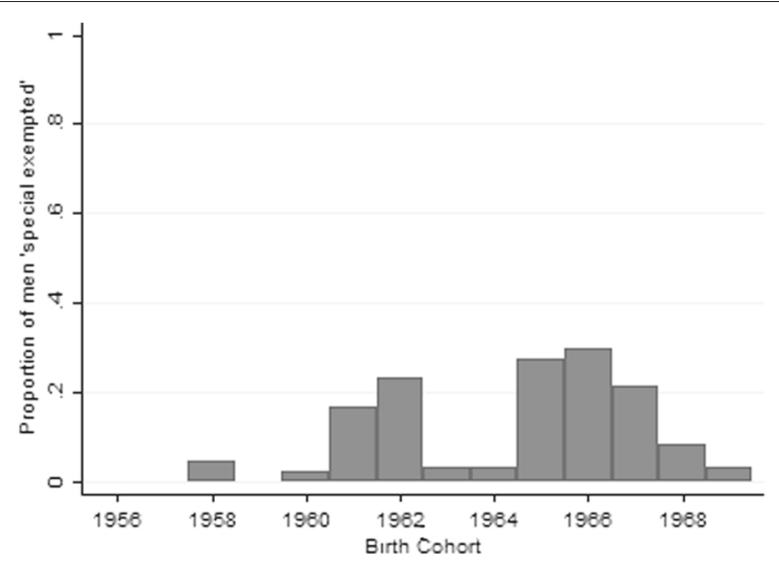

Figure 2 Proportion of Dutch men in the category 'Special Exemption' by birth cohort. 
Table 1 Summary statistics

\begin{tabular}{lllll}
\hline Conscription & $(\mathbf{1})$ & $\mathbf{( 2 )}$ & $\mathbf{( 3 )}$ & $\mathbf{( 4 )}$ \\
Birth cohort & No & Yes & Yes & Yes \\
\hline Age & Cohort 1959 & $\mathbf{\pm 1 \text { cohort }}$ & $\mathbf{\pm 2 \text { cohorts }}$ & $\mathbf{\pm} \mathbf{3}$ cohorts \\
Years of completed education & 38.1 & 38.0 & 38.0 & 38.1 \\
Tertiary education (\%) & 13.3 & 13.3 & 13.3 & 13.2 \\
$\quad$ Higher professional education (\%) & 22.1 & 32.6 & 32.6 & 32.6 \\
$\quad$ University degree (\%) & 12.3 & 21.7 & 21.8 & 21.8 \\
Gross annual wages (in 1000 euro) & 28.5 & 28.0 & 10.8 & 10.8 \\
Served in the army (\%) & 0 & 44.1 & 28.0 & 28.0 \\
Special exemption status (\%) & 0 & 3.5 & 39.9 & 39.4 \\
\hline
\end{tabular}

Note: Columns (2), (3) and (4) contain, respectively, one, two or three cohorts before and after birth cohort 1959, but do not include cohort 1959.

\subsection{Conscription and educational attainment}

Table 2 shows the estimated effects of military conscription on educational attainment using the local approach. We use three different schooling outcomes: years of completed schooling (top panel), obtaining a degree of higher professional education (middle panel) and obtaining a university degree (bottom panel). As mentioned before, tertiary education in the Netherlands consists of two levels: higher professional education and university education. We look specifically at the effects on tertiary education as the transition from secondary education coincides with the period that Dutch conscripts are called to serve in the army. In addition, completion of tertiary education might be a route for avoiding military conscription. Each panel of Table 2 shows reduced form estimates and IV-estimates for discontinuity samples of one, two and three years around 1959. For each discontinuity sample, we show the results of a linear and quadratic specification of age.

All point estimates in Table 2 suggest a negative effect of conscription on investment in human capital. However, the estimated effects on years of schooling and on the probability of obtaining a degree of higher professional education are statistically insignificant. The estimated effects on obtaining a university degree show a different picture; military conscription harms the probability of obtaining a university degree. Males born in 1959 are 1.5 percentage points more likely to obtain a university degree than those born in

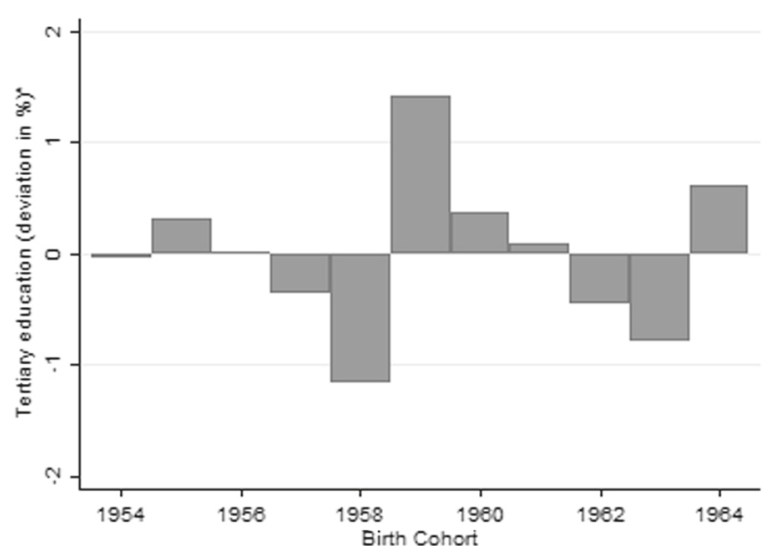

Figure 3 Completion of tertiary education of males by birth cohort adjusted for time trend. 


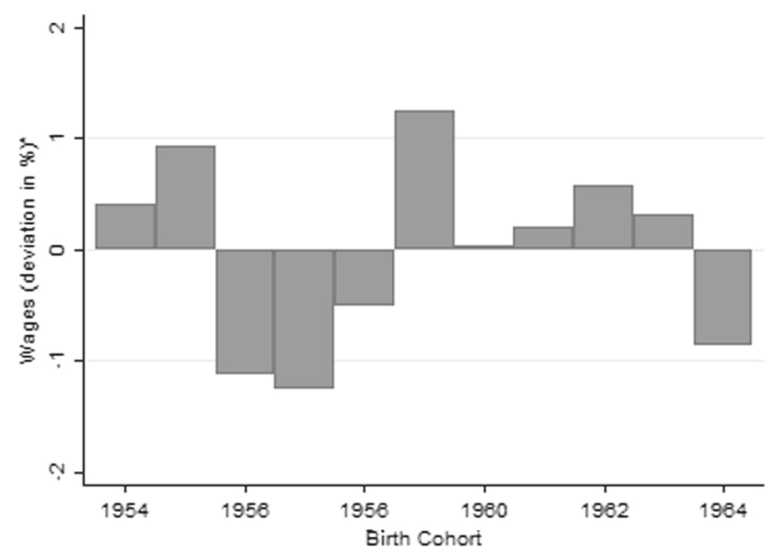

Figure 4 Log gross annual wages of males by birth cohort adjusted for time trend.

the adjacent three years. This implies that the system of military conscription causes a reduction of university education completion from 12.3 to 10.8 per cent. If there had not been a system of military conscription, the proportion of male university graduates in the adjacent three cohorts before and after 1959 would have been 1.5 percentage points higher. This reduction probably induces substantial societal costs as tertiary education is often considered to be important for social welfare and economic growth (Hanushek and Woessmann 2008). The IV-estimates are obtained through a rescaling of the reduced form estimates with the proportion of conscripts per birth cohort. These estimates suggest that the impact for the compliers, those that would serve if they were not born in

Table 2 Reduced form and IV estimates of the effect of military service on investments in human capital

\begin{tabular}{|c|c|c|c|c|c|c|}
\hline \multirow[b]{2}{*}{ Years of completed education } & \multicolumn{2}{|c|}{ \pm 1 birth cohort } & \multicolumn{2}{|c|}{ \pm 2 birth cohorts } & \multicolumn{2}{|c|}{ \pm 3 birth cohorts } \\
\hline & (1) & $(2)$ & (3) & (4) & $(5)$ & (6) \\
\hline \multirow[t]{2}{*}{ Reduced form } & -0.019 & -0.026 & -0.041 & -0.044 & -0.059 & -0.064 \\
\hline & $(0.044)$ & $(0.044)$ & $(0.040)$ & $(0.041)$ & $(0.039)$ & $(0.040)$ \\
\hline \multirow[t]{2}{*}{ IV } & -0.043 & -0.059 & -0.064 & -0.069 & -0.084 & -0.091 \\
\hline & $(0.10)$ & $(0.10)$ & $(0.098)$ & $(0.099)$ & $(0.095)$ & $(0.095)$ \\
\hline Higher professional education (\%) & (1) & $(2)$ & (3) & (4) & $(5)$ & (6) \\
\hline \multirow[t]{2}{*}{ Reduced Form } & -0.003 & -0.004 & -0.003 & -0.002 & -0.003 & -0.002 \\
\hline & $(0.007)$ & $(0.007)$ & $(0.006)$ & $(0.006)$ & $(0.006)$ & $(0.006)$ \\
\hline \multirow[t]{2}{*}{ IV } & -0.008 & -0.009 & -0.006 & -0.005 & -0.006 & -0.005 \\
\hline & $(0.015)$ & $(0.015)$ & $(0.015)$ & $(0.015)$ & $(0.014)$ & $(0.014)$ \\
\hline University education (\%) & $(1)$ & $(2)$ & (3) & (4) & $(5)$ & (6) \\
\hline \multirow[t]{2}{*}{ Reduced form } & $-0.015^{* * *}$ & $-0.016^{* * *}$ & $-0.015^{* * *}$ & $-0.015^{* * *}$ & $-0.015^{* * *}$ & $-0.016^{* * *}$ \\
\hline & $(0.005)$ & $(0.0051)$ & $(0.0046)$ & $(0.0046)$ & $(0.0044)$ & $(0.0044)$ \\
\hline \multirow[t]{2}{*}{ IV } & $-0.033^{* * *}$ & $-0.035^{* * *}$ & $-0.035^{* * *}$ & $-0.035^{* * *}$ & $-0.030^{* * *}$ & $-0.033^{* * *}$ \\
\hline & $(0.011)$ & $(0.011)$ & $(0.011)$ & $(0.011)$ & $(0.011)$ & $(0.011)$ \\
\hline Age polynomials & Linear & Quadratic & Linear & Quadratic & Linear & Quadratic \\
\hline Observations & 17,605 & 17,605 & 29,228 & 29,228 & 40,481 & 40,481 \\
\hline
\end{tabular}

Notes: Each cell is based on a separate regression of education on military conscription as specified in Equations (2) and (4). Standard errors in parentheses: ${ }^{* * *} \mathrm{p}<0.01$. 
1959, is approximately 3-4 percentage points. The estimates are robust for the discontinuity sample or the specification of age. The estimated effects do not change when we use non-linear models instead of linear probability models.

In sum, we find that military conscription seems to have a substantial societal cost by reducing the proportion of young males that obtain a university degree in the Netherlands. In addition, conscription also generates private costs by reducing the probability of completing university education for conscripts. Our results are different from earlier studies that found positive effects of military conscription on educational attainment because of draft avoidance behaviour (Bauer et al. 2014; Card and Lemieux 2001; Maurin and Xenogiani 2007). However, other studies also found negative effects of conscription on educational attainment (Buonanno 2006; Di Pietro 2013). A factor that might be important in the Dutch context is that students that (temporarily) drop-out from their university education have to fulfill their military service before being allowed to reenroll. This might have affected the proportion of university graduates as this creates an interruption in the educational career of these students.

\subsection{Conscription and earnings}

The estimated effects of military conscription on $(\log )$ annual earnings are shown in Table 3 using the same models and estimation samples as in Table 2. The reduced form estimates show that males born in 1959 earn, on average, 1.5 per cent more than those born in the adjacent one, two or three years. This implies that an abolishment of the

Table 3 Reduced form and IV estimates of the effect of military service on log annual wages 1

\begin{tabular}{|c|c|c|c|c|c|c|}
\hline \multirow[b]{2}{*}{ Log annual wages } & \multicolumn{2}{|c|}{ \pm 1 birth cohort } & \multicolumn{2}{|c|}{ \pm 2 birth cohorts } & \multicolumn{2}{|c|}{ \pm 3 birth cohorts } \\
\hline & (1) & (2) & (3) & (4) & (5) & (6) \\
\hline \multirow[t]{2}{*}{ Reduced form } & $-0.013^{*}$ & $-0.013^{*}$ & $-0.017^{* *}$ & $-0.015^{* *}$ & $-0.019 * * *$ & $-0.017^{* *}$ \\
\hline & $(0.008)$ & $(0.008)$ & $(0.007)$ & $(0.007)$ & $(0.007)$ & $(0.007)$ \\
\hline \multirow[t]{2}{*}{ IV } & $-0.031^{*}$ & $-0.029^{*}$ & $-0.036^{* *}$ & $-0.032^{*}$ & $-0.038^{* *}$ & $-0.033^{* *}$ \\
\hline & $(0.017)$ & $(0.018)$ & $(0.017)$ & $(0.017)$ & $(0.017)$ & $(0.017)$ \\
\hline Log annual wages & (1) & $(2)$ & (3) & (4) & (5) & (6) \\
\hline \multirow[t]{2}{*}{ Reduced form } & $-0.013^{*}$ & -0.011 & $-0.015^{* *}$ & $-0.013^{*}$ & $-0.016^{* *}$ & $-0.013^{* *}$ \\
\hline & $(0.007)$ & $(0.007)$ & $(0.007)$ & $(0.007)$ & $(0.007)$ & $(0.007)$ \\
\hline \multirow[t]{2}{*}{ IV } & $-0.028^{*}$ & -0.026 & $-0.033^{* *}$ & $-0.029^{*}$ & $-0.034^{* *}$ & $-0.028^{*}$ \\
\hline & $(0.017)$ & $(0.017)$ & $(0.016)$ & $(0.016)$ & $(0.016)$ & $(0.016)$ \\
\hline \multirow[t]{2}{*}{ Control: Years of education } & $0.051^{* * *}$ & $0.051^{* * *}$ & $0.049^{* * *}$ & $0.049^{* * *}$ & $0.049^{* * *}$ & $0.049^{* * *}$ \\
\hline & $(0.001)$ & $(0.001)$ & $(0.001)$ & $(0.001)$ & $(0.001)$ & $(0.001)$ \\
\hline Log annual wages & (1) & (2) & (3) & (4) & (5) & (6) \\
\hline \multirow[t]{2}{*}{ Reduced form } & -0.008 & -0.007 & $-0.012^{*}$ & -0.010 & $-0.014^{* *}$ & $-0.011^{*}$ \\
\hline & $(0.007)$ & $(0.008)$ & $(0.007)$ & $(0.007)$ & $(0.007)$ & $(0.007)$ \\
\hline \multirow[t]{2}{*}{ IV } & -0.019 & -0.017 & -0.024 & -0.021 & $-0.028^{*}$ & -0.022 \\
\hline & $(0.017)$ & $(0.017)$ & $(0.017)$ & $(0.017)$ & $(0.016)$ & $(0.016)$ \\
\hline \multirow[t]{2}{*}{ Control: University education } & $0.348^{* * *}$ & $0.348^{* * *}$ & $0.339^{* * *}$ & $0.339^{* * *}$ & $0.331^{* * *}$ & $0.331^{* * * 1}$ \\
\hline & $(0.011)$ & $(0.011)$ & $(0.009)$ & $(0.009)$ & $(0.008)$ & $(0.008)$ \\
\hline Age polynomials & linear & quadratic & linear & quadratic & linear & quadratic \\
\hline Observations & 17,605 & 17,605 & 29,228 & 29,228 & 40,481 & 40,481 \\
\hline
\end{tabular}

Notes: Each cell is based on a separate regression of wages on military conscription as specified in Equations (2) and (4). Standard errors in parentheses: ${ }^{* *} p<0.01,{ }^{* *} p<0.05,{ }^{*} p<0.1$. 
system of compulsory military service would increase average male earnings for these cohorts by 1.5 per cent. At the individual level, the long term cost of conscription for compliers is approximately 3 to 4 per cent. The average age in our sample is approximately 38 years, which implies that 18 years after conscription, men that had to serve as recruits still earn 3-4 per cent less than those who didn't. Imbens and van der Klaauw (1995) estimate a negative effect of 4-5 per cent on wages 10 years after conscription.

\subsection{Conscription, education and earnings}

Next we investigate to what extent the negative effect of conscription on wages is driven by the effects on educational attainment. In Table 3 estimates are shown of the 'wage' models that include years of schooling (middle panel) or university degree (lower panel) as additional controls. These controls aim to pick up the effects of conscription that work through education. Hence, the remaining effects of conscription on wages are not driven by differential investments in human capital. The estimates show that the estimated effect of conscription reduces after controlling for years of schooling or controlling for completion of university education. However, the effect of conscription on earnings remains substantial and statistically significant. This suggests that conscription also reduces individual earnings capacities through other channels other than human capital obtained in the schooling system.

\section{Sensitivity analysis}

In this section, we investigate the robustness of the previous findings. First, we will estimate the same models as Imbens and van der Klaauw (1995) using individual level data until 2002. These models not only exploit the variation from the birth cohort 1959 but also the variation in military conscription between other birth cohorts. Second, we re-estimate the main models for the sample of women. As women are exempted from military service, we do no expect differences between birth cohorts. This analysis can be considered as a placebo test for our main estimates. Third, we will investigate how the drop in university graduates for birth cohort 1958 affects our estimates.

\subsection{Replication of Imbens and van der Klaauw (1995)}

Imbens and van der Klaauw (1995) exploited two types of variation. First, they used the variation in the proportion of conscripts from 14 birth cohorts. Second, they used the variation in the proportion that received a special exemption status. The special exemption status was first introduced for birth cohort 1958. Therefore, Imbens and van der Klaauw (1995) did not use the birth cohorts 1956 and 1957 in the analysis that exploited this type of variation. In our replication, we use exactly the same variation and the same birth cohorts as Imbens and van der Klaauw (1995). Table 4 shows the estimation results of the effects of military conscription on educational attainment and earnings using the same specifications as Imbens and van der Klaauw (1995). The estimation sample consists of individuals from 14 birth cohorts. The estimation results in the first row for each dependent variable (conscripted) exploit variation in the proportion of individuals within birth cohorts that actually served. The estimation results in the second row (status 'special exemption') exploit variation in the proportion of individuals within birth cohorts that did not serve due to a 'special exemption' status. We estimated Equation (4) from Section (4), which included the proportion of young men that served or the proportion 
Table 4 IV-estimates of the long term effect of conscription on education and earnings using the model of (1995)

\begin{tabular}{lll}
\hline Years of completed education & $\mathbf{( 1 )}$ & $\mathbf{( 2 )}$ \\
\hline Conscripted & -0.080 & -0.075 \\
Status 'special exemption' & $(0.085)$ & $(0.086)$ \\
& 0.046 & 0.046 \\
\hline Higher professional education & $(0.051)$ & $(0.051)$ \\
\hline Conscripted & $\mathbf{( 1 )}$ & $\mathbf{( 2 )}$ \\
\hline Status 'special exemption' & -0.013 & -0.012 \\
\hline University education & $(0.013)$ & $(0.013)$ \\
\hline Conscripted & 0.010 & 0.010 \\
\hline Status 'special exemption' & $\mathbf{( 1 )}$ & $\mathbf{( 2 )}$ \\
\hline Log annual wages & $-0.022^{* *}$ & $-0.018^{*}$ \\
\hline Conscripted & $(0.0097)$ & $(0.0097)$ \\
& $0.014^{* *}$ & $0.015^{* * *}$ \\
Status 'special exemption' & $(0.0058)$ & $(0.0058)$ \\
\hline Age polynomials & $(\mathbf{1})$ & $\mathbf{( 2 )}$ \\
\hline
\end{tabular}

Notes: Each cell is based on a separate regression and uses variation in the proportion of conscripts or variation in the proportion having special exemption status between cohorts. The number of observations in the first regression is 73,892 ; for the second type of regressions this is 62,243 (the birth cohorts of 1956 and 1957 are not included). Standard errors in parentheses: ${ }^{* * *} p<0.01,{ }^{* *} p<0.05,{ }^{*} p<0.1$.

of young men that had a special exemption status within birth cohorts as the main independent variable. We estimated these models using a linear or a quadratic specification of age. The estimation results in Table 4 confirm the previous findings. Serving in the army has a negative, but statistically insignificant, effect on years of schooling and graduation from higher professional education. Serving in the army reduces the probability of obtaining a university degree and also reduces long term earnings. These effects are statistically significant for both types of variation with one exemption. The size of the effects on university completion is somewhat smaller than the results from the local approach. The effects on wages are comparable when using a quadratic specification. In sum, exploiting all variation between birth cohorts gives similar results, but the effects on university education are smaller. This implies that the variation used from cohorts further away from the policy change that affected the birth cohort of 1959 has less impact on the completion of university education. This variation is, however, less well understood than the variation used in the analysis of Section 6.

\subsection{Placebo test on women}

Conscription was compulsory for men, but not for women. If other factors are important for the schooling or wage differences between birth cohorts, these factors might also affect schooling and earnings of women. To investigate the importance of other factors, we re-estimate the main models from Tables 2 and 3 using a sample of women only. The results are shown in Table 5 . The estimates of the effect on obtaining a university degree are close to zero and sometimes positive. This suggest that the difference in obtaining a 
Table 5 Reduced form and IV estimates of conscription on sample of women (sensitivity)

\begin{tabular}{|c|c|c|c|c|c|c|}
\hline \multirow[b]{2}{*}{ University education (\%) } & \multicolumn{2}{|c|}{ \pm 1 birth cohort } & \multicolumn{2}{|c|}{ \pm 2 birth cohorts } & \multicolumn{2}{|c|}{ \pm 3 birth cohorts } \\
\hline & $(1)$ & $(2)$ & $(3)$ & $(4)$ & $(5)$ & $(6)$ \\
\hline \multirow[t]{2}{*}{ Reduced form } & 0.007 & 0.009 & 0.004 & 0.005 & 0.003 & 0.004 \\
\hline & $(0.012)$ & $(0.012)$ & $(0.011)$ & $(0.011)$ & $(0.011)$ & $(0.011)$ \\
\hline \multirow[t]{2}{*}{ IV } & 0.008 & 0.010 & 0.002 & 0.002 & -0.001 & -0.000 \\
\hline & $(0.013)$ & $(0.013)$ & $(0.012)$ & $(0.012)$ & $(0.011)$ & $(0.011)$ \\
\hline Log annual wages & $(1)$ & $(2)$ & (3) & (4) & (5) & (6) \\
\hline \multirow[t]{2}{*}{ Reduced form } & -0.013 & -0.014 & -0.007 & -0.008 & -0.003 & -0.008 \\
\hline & $(0.013)$ & $(0.013)$ & $(0.012)$ & $(0.012)$ & $(0.011)$ & $(0.011)$ \\
\hline \multirow[t]{2}{*}{ IV } & -0.028 & -0.031 & -0.023 & -0.025 & -0.016 & -0.025 \\
\hline & $(0.029)$ & $(0.030)$ & $(0.029)$ & $(0.029)$ & $(0.027)$ & $(0.028)$ \\
\hline Age polynomials & Linear & Quadratic & Linear & Quadratic & Linear & Quadratic \\
\hline Observations & 12,761 & 12,761 & 21,448 & 21,448 & 29,960 & 29,960 \\
\hline
\end{tabular}

Each cell is based on a separate regression of education and wages on military conscription as specified in Equations (2) and (4). Standard errors in parentheses.

university degree for males born in 1959 and males born in adjacent years is not driven by unobserved factors that increase university enrolment for those born in 1959. We also do not find statistically significant effects on female wages. Hence, we do not find evidence for the importance of unobserved factors that might have an effect on educational attainment or earnings.

It should be noted that this placebo test is not completely clean as women may have been indirectly affected by military conscription. For instance, women might face less competition from men on the labour market due to conscription. Moreover, for married women, there might be substitution or income effects related to the direct effects of conscription on their husbands. These indirect effects will probably be more important for women's wages than for the education of women because of the timing of the effects.

\subsection{A lower proportion of university graduates in birth cohort 1958}

Our model relies on the assumption that men born in birth year 1959 are similar to those in the adjacent years. However, Figure 3 shows that the proportion of university graduates is remarkably lower for those born in 1958 than in adjacent birth cohorts. This may affect our estimates of the effect of conscription on university graduation. Therefore we conduct two sensitivity analyses. First, we re-estimate the effect of military service on the probability to complete university education while excluding birth cohort 1958 and including an earlier birth cohort. The estimates are shown in the upper panel of Table 6. Second, we pool the data of males and females and estimate specifications of Equations (2) and (4) that include a dummy for males and an interaction between birth cohort 1959 and males. Hence, this provides a difference-in-differences estimate of the effect of conscription on completion of education. The lower panel of Table 6 shows the difference-in-differences estimates for Equations (2) and (4). We observe that the estimates in both panels are very similar to the estimates in Table 2 . This implies that the drop in the proportion of university graduates of birth cohort 1958 does not affect the main estimation results.

\section{Conclusions}

This paper investigated the long-term effect of military conscription on educational attainment and wages by exploiting a policy change that exempted a complete birth 
Table 6 Sensitivity analysis of the effect of conscription on university graduation

\begin{tabular}{|c|c|c|c|c|c|c|}
\hline \multirow[b]{2}{*}{$\begin{array}{l}\text { Panel 1: Excluding birth } \\
\text { cohort } 1958\end{array}$} & \multicolumn{2}{|c|}{ \pm 1 birth cohort } & \multicolumn{2}{|c|}{ \pm 2 birth cohorts } & \multicolumn{2}{|c|}{ \pm 3 birth cohorts } \\
\hline & (1) & (2) & (3) & (4) & (5) & (6) \\
\hline \multirow[t]{2}{*}{ Reduced form } & $-0.014^{* * *}$ & $-0.015^{* * *}$ & $-0.013^{* * *}$ & $-0.014^{* * *}$ & $-0.015^{* * *}$ & $-0.016^{* * *}$ \\
\hline & $(0.0052)$ & $(0.0052)$ & $(0.0046)$ & $(0.0047)$ & $(0.0044)$ & $(0.0045)$ \\
\hline \multirow[t]{2}{*}{ IV } & $-0.033^{* * *}$ & $-0.036^{* * *}$ & $-0.028^{* *}$ & $-0.031^{* * *}$ & $-0.030^{* * *}$ & $-0.033^{* * *}$ \\
\hline & $(0.012)$ & $(0.012)$ & $(0.011)$ & $(0.011)$ & $(0.011)$ & $(0.011)$ \\
\hline Observations & 17,527 & 17,527 & 29,059 & 29,059 & 40,367 & 40,367 \\
\hline $\begin{array}{l}\text { Panel 2: Difference-in-differences } \\
\text { estimates }\end{array}$ & (1) & (2) & (3) & (4) & (5) & (6) \\
\hline \multirow[t]{2}{*}{ Reduced form } & $-0.018^{* *}$ & $-0.018^{* *}$ & $-0.015^{* *}$ & $-0.015^{* *}$ & $-0.014^{* *}$ & $-0.015^{* *}$ \\
\hline & $(0.007)$ & $(0.007)$ & $(0.007)$ & $(0.007)$ & $(0.006)$ & $(0.006)$ \\
\hline \multirow[t]{2}{*}{ IV } & $-0.040^{* *}$ & $-0.040^{* *}$ & $-0.039 * *$ & $-0.039 * *$ & $-0.031^{* *}$ & $-0.031^{* *}$ \\
\hline & $(0.017)$ & $(0.017)$ & $(0.016)$ & $(0.016)$ & $(0.015)$ & $(0.015)$ \\
\hline Age polynomials & Linear & Quadratic & Linear & Quadratic & Linear & Quadratic \\
\hline Observations & 30,366 & 30,366 & 50,676 & 50,676 & 70,441 & 70,441 \\
\hline
\end{tabular}

Notes: In Panel 1, each cell is based on a separate regression of education on military conscription as specified in Equations (2) and (4) on a sample excluding birth cohort 1958 and including an earlier birth cohort. In Panel 2, each column shows the difference-in-differences estimates of the effect of conscription using the pooled sample of men and women. Standard errors in parentheses: ${ }^{* * *} \mathrm{p}<0.01,{ }^{* *} \mathrm{p}<0.05$.

cohort from military service. We compare the educational outcomes and earnings of the exempted cohort with the outcomes of men from adjacent cohorts. This local approach yields estimates of the societal costs of a system of military conscription and estimates of the private costs for individuals that had to serve in the military. Our approach is related to previous work by Imbens and van der Klaauw (1995), who investigated the effects of conscription on wages of conscripts until 1990.

We find that the system of compulsory military service decreases the proportion of university graduates by 1.5 percentage points from a baseline of 12.3 per cent. In addition, being a conscript reduces the probability of obtaining a university degree by almost four percentage points. Our estimates also show that the system of military service reduces average societal wages by 1.5 per cent. The private costs for conscripts are higher; they lose approximately 3 to 4 per cent of their wages by serving in the military. The fact that the average man in our sample served in the army almost 18 years before suggests that the negative effects of military service are long-lasting. Finally, we find that the effect of conscription on educational attainment does not fully explain the wage reduction. This suggests that conscription also reduces individual earnings capacity through channels other than a reduction in human capital.

This study provides a new piece of evidence about the hidden costs of conscription. Our estimates show that military conscription has long term negative consequences for completion of university education and for individual earnings. This implies that the costs of conscription are substantial, both at the societal level and at the individual level. Moreover, the private costs of conscription seem to be long-lasting.

\section{Endnotes}

${ }^{1}$ A recent study finds no effect on university enrolment of the abolition of compulsory military service in Italy (Di Pietro 2013).

${ }^{2}$ Although the Netherlands abandoned military conscription in 1997, every Dutch man still has a military obligation. Since 1997 however, recruits are no longer called to serve. We may regard this as a 100 per cent exemption rate. 
${ }^{3}$ This description refers to the the procedures and ages in regard to the military conscription after the policy change in 1977.

${ }^{4}$ Gelman and Imbens (2014) advocate the use of local approaches in regression discontinuity models and show that estimates based on higher-order polynomials of the forcing variable can be misleading.

5 "LSO" is an abbreviation of the Dutch word "Loonstructuuronderzoek".

\section{Abbreviation}

LSO: Loonstructuuronderzoek (Wage Structure Survey).

\section{Competing interests}

The IZA Journal of Labor Economics is committed to the IZA Guiding Principles of Research Integrity. The authors declare that they have observed these principles.

\section{Acknowledgments}

We thank the editor Pierre Cahuc and two anonymous referees for their constructive comments.

Responsible editor: Pierre Cahuc.

\section{Author details}

${ }^{1}$ Erasmus School of Economics, Rotterdam, Netherlands. ${ }^{2}$ Tinbergen Institute, Amsterdam, Netherlands. ${ }^{3}$ IZA Bonn, Bonn, Germany.

Received: 6 November 2014 Accepted: 26 January 2015

Published online: 26 May 2015

\section{References}

Angrist JD (1990) Lifetime earnings and the vietnam era draft lottery: Evidence from social security administrative records. Am Econ Rev 80(3):313-336

Angrist JD, Chen SH, Song J (2011) Long-term consequences of Vietnam-era conscription: New estimates using social security data. Am Econ Rev 101(3):334-338

Angrist JD, Krueger AB (1994) Why do World War II veterans earn more than nonveterans? Am Econ Rev 12(1):74-97

Bauer TK, Bender S, Paloyo AR, Schmidt CM (2012) Evaluating the labor-market effects of compulsory military service. Eur Econ Rev 56(4):814-829

Bauer TK, Bender S, Paloyo AR, Schmidt CM (2014) Do guns displace books? the impact of compulsory military service on educational attainment. Econ Lett 124(3):513-515

Buonanno P (2006) Long-term effects of conscription: Lessons from the UK. University of Bergamo, Department of Economics, Working Paper 0604

Card D, Lemieux T (2001) Going to college to avoid the draft: The unintended legacy of the Vietnam War. Am Econ Rev 91(2):97-102

Cipollone P, Rosolia A (2007) Social interactions in high school: Lessons from an earthquake. Am Econ Rev 97(3):948-965

Di Pietro G (2013) Military conscription and university enrolment: Evidence from Italy. J Population Econ 26(2):619-644

Duindam S (1995) Militaire dienstplicht: Een economische analyse van de personeelscomponent in de krijgsmacht. Dissertation, University of Limburg

Gelman A, Imbens G (2014) Why high-order polynomials should not be used in regression discontinuity designs. Technical report, National Bureau of Economic Research working paper 2505

Grenet J, Hart RA, Roberts E (2010) Above and beyond the call. Long-term real earnings effects of British male military conscription in the post-war years. Labour Econ 18:194-204

Hanushek EA, Woessmann L (2008) The role of cognitive skills in economic development. J Econ Literature 46(3):607-668 Hoffenaar J, Schoenmaker B (1994) Met de blik naar het oosten: De Koninklijke Landmacht 1945-1990. Historical Section of the Royal Netherlands Army, The Hague

Imbens G, van der Klaauw W (1995) Evaluating the cost of conscription in the Netherlands. J Bus Econ Stat 13(2):207-215

Keller KR, Poutvaara P, Wagener A (2009) Does military draft discourage enrollment in higher education? Evidence from OECD countries. IZA discussion paper 4399

Lau M, Poutvaara P, Wagener A (2004) The dynamic cost of the draft. German Econ Rev 5(4):381-406

Maurin E, Xenogiani T (2007) Demand for education and labor market outcomes: Lessons from the abolition of compulsory conscription in France. J Human Resour 42(4):795-819

Poutvaara P, Wagener A (2011) The political economy of conscription. In: Coyne CJ, Mathers RL (eds). The Handbook on the Political Economy of War. Edward Elgar Publishing, Cheltenham (UK). pp 154-172

Poutvaara P, Wagener A (2007) To draft or not to draft? Inefficiency, generational incidence, and political economy of military conscription. Eur J Political Economy 23(4):975-987

Siminski P (2013) Employment effects of army service and veterans' compensationevidence from the Australian Vietnam-era conscription lotteries. Rev Econ Stat 95(1):87-97 